Cite this: Phys. Chem. Chem. Phys., 2013, 15, 12551

Received 22nd December 2012 Accepted 7th May 2013

DOI: $10.1039 / c 3 c p 44653 k$

www.rsc.org/pccp

\title{
Hydrogen bonding involving side chain exchangeable groups stabilizes amyloid quarternary structure
}

\author{
Vipin Agarwal, $\dagger^{\mathrm{a}}$ Rasmus Linser,$^{t^{\mathrm{a}}}$ Muralidhar Dasari, ${ }^{\text {abc }}$ Uwe Fink, $^{\mathrm{a}}$ \\ Juan-Miguel Lopez del Amoß $\S^{\text {abc }}$ and Bernd Reif*abc
}

\begin{abstract}
The amyloid $\beta$-peptide $(A \beta)$ is the major structural component of amyloid fibrils in the plaques of brains of Alzheimer's disease patients. Numerous studies have addressed important aspects of secondary and tertiary structure of fibrils. In electron microscopic images, fibrils often bundle together. The mechanisms which drive the association of protofilaments into bundles of fibrils are not known. We show here that amino acid side chain exchangeable groups like e.g. histidines can provide useful restraints to determine the quarternary assembly of an amyloid fibril. Exchangeable protons are only observable if a side chain hydrogen bond is formed and the respective protons are protected from exchange. The method relies on deuteration of the $A \beta$ peptide. Exchangeable deuterons are substituted with protons, before fibril formation is initiated.
\end{abstract}

Alzheimer's disease (AD) is a slowly progressive neurological disorder which is associated with memory loss, cognitive impairment and finally dementia and death. The amyloid $\beta$-peptide $(\mathrm{A} \beta)$ is the major structural component of amyloid fibrils in the plaques of brains of Alzheimer's disease patients. $\mathrm{A} \beta$ is a cleavage product resulting from Alzheimer Precursor Protein (APP) processing. ${ }^{1}$ The $\gamma$-secretase cut yields A $\beta$ fragments of different lengths of which $\mathrm{A} \beta 40$ and $\mathrm{A} \beta 42$ are most abundant. ${ }^{2,3}$ In vitro, the $\mathrm{A} \beta$ peptide aggregates over time into oligomers and fibrillar structures. ${ }^{4}$ In the past, several $A \beta$ fibril structure models have been suggested. These are based on MAS solidstate NMR experiments, ${ }^{5-11}$ and cryo-electron microscopic image reconstructions. ${ }^{12}$ Even though there is some controversy concerning the conformational space that $A \beta$ fibrils can adopt, all published models, including the 2 -fold ${ }^{7,10}$ and 3 -fold ${ }^{9}$ symmetric $A \beta^{1-40}$ fibril structure suggested by Tycko, and Bertini and co-workers, agree on the basic building block which

\footnotetext{
${ }^{a}$ Leibniz-Institut für Molekulare Pharmakologie (FMP), Robert-Rössle-Str. 10, 13125 Berlin-Buch, Germany. E-mail: reif@tum.de

${ }^{b}$ Munich Center for Integrated Protein Science (CIPSM) at Department Chemie, Technische Universität München (TUM), Lichtenbergstr. 4, 85747 Garching, Germany

${ }^{c}$ Helmholtz-Zentrum München (HMGU), Deutsches Forschungszentrum für Gesundheit und Umwelt, Ingolstädter Landstr. 1, 85764 Neuherberg, Germany † Current Address: ETH Zürich, Laboratorium für Physikalische Chemie, WolfgangPauli-Str. 10, CH-8093 Zürich, Switzerland.

$\ddagger$ Current Address: Harvard Medical School, 240 Longwood Avenue, Boston, MA 02115, USA.

$\S$ Current Address: CIC Energigune, Albert Einstein 48, 01510 Miñano (Álava), Spain.
}

involves a $\beta$-sheet ( $\beta 1$, residues 12-24), a turn, and a second $\beta$-sheet $(\beta 2$, residues $28-40)$. Biophysical studies indicate a certain degree of conformational plasticity for the $\mathrm{N}$-terminal $\beta$-sheet. ${ }^{13,14}$ Whereas $\beta 2$ is present in all the studies, $\beta 1$ can be truncated or does not adopt a regular $\beta$-sheet structure. Depending on the preparation conditions, amide protons in the region of the peptide where the first $\beta$-strand is expected show differential H/D protection factors. ${ }^{13}$ Similarly, a certain degree of conformational variability in the $\mathrm{N}$-terminus is suggested using cryo-electron microscopy. ${ }^{14}$ In all structural models, A $\beta$ peptides are arranged in a parallel fashion. An antiparallel arrangement is only observed for the Iowa mutant $\mathrm{A} \beta-\mathrm{D} 23 \mathrm{~N},{ }^{15}$ and for truncated forms of the peptide such as $\mathrm{A} \beta^{11-25} \cdot{ }^{16}$ The fibril structure is stabilized in particular by hydrogen bonding interactions. Therefore, observation of exchangeable and titratable groups is of particular interest to identify hydrogen bonding patterns. We and others could show in the past that high resolution proton spectra can be obtained for crystalline proteins, ${ }^{17-22}$ as well as for amyloid fibrils and membrane proteins. ${ }^{23,24}$ Due to the fact that magnetization transfer via dipolar interactions is very efficient, quickly exchanging side chain hydroxyl protons can be observed and assigned easily. ${ }^{25}$ At the same time, scalar coupling based experiments yield reliable resonance assignments in the solid-state. ${ }^{26-29}$ Fibril samples prepared from deuterated $A \beta$ peptides allow us to collect long range distance restraints which will help to refine the quarternary structure of the fibril..$^{30,31}$ In the long run, this labeling scheme will allow an artifact-free quantification of dynamics in the solid-state without spin diffusion as a potential 
source of error. ${ }^{21,32}$ The registry of monomers which are concatenated in the amyloid fibril via backbone hydrogen bonds is restrained employing backbone-backbone correlations from XHHY (X, Y $={ }^{13} \mathrm{C}$ or $\left.{ }^{15} \mathrm{~N}\right)$ type experiments. ${ }^{33,34}$ To differentiate between intramolecular and intermolecular contacts, exclusively ${ }^{15} \mathrm{~N}$ labeled protein is mixed with a selectively ${ }^{13} \mathrm{C}^{\alpha}$ labeled sample. ${ }^{35}$ These experiments yield the structure of the monomeric fibril building unit, and the arrangement of the peptide strands along the fibril axis. To determine the orientation of different protofilaments with respect to one another, side chain interactions need to be analyzed. This information can be obtained e.g. from HMQC-RFDR type experiments. ${ }^{20}$ In the past, we have shown that for perdeuterated proteins it is possible to identify the donor and acceptor moieties of side chains involved in hydrogen bonds using a sufficiently long $\mathrm{CP} .^{25}$ For $\mathrm{A} \beta$, hydrophobic interactions in the C-terminus yield an antiparallel arrangement of the protofilaments. ${ }^{7}$ The other face of the protofilament is more hydrophilic, and is not involved in tertiary contacts in the models presented so far.

We show here that exchangeable side chain protons can assist in defining the quarternary structure of the fibril assembly. Side chain exchangeable protons are only observable if they are involved in a hydrogen bond such that the respective proton is protected from exchange. The chemical shifts of these imidazole protons together with geometric information from dipolar coupling measurements will yield further information on the nature of these hydrogen bonds.

\section{Experimental procedures}

Expression of uniformly $\left[{ }^{2} \mathrm{D},{ }^{15} \mathrm{~N},{ }^{13} \mathrm{C}\right]$-labeled $\mathrm{A} \beta^{1-40}$ was achieved by recombinant expression in $E$. coli (BL21 DE3), using a p28a vector (Novagen) carrying an insert encoding the $A \beta^{1-40}$ sequence. Expression tests were performed in LB, subsequent expression of labelled protein was done in isotopically enriched minimal medium (1.0 $\mathrm{g} \mathrm{L}^{-1}{ }^{15} \mathrm{NH}_{4} \mathrm{Cl}, 2 \mathrm{~g} \mathrm{~L}^{-113} \mathrm{C}$ glucose) containing $50 \mathrm{mg} \mathrm{L}^{-1}$ kanamycin. Cells were grown to an $\mathrm{OD}_{600}$ of 0.6 at $37^{\circ} \mathrm{C}$ and induced using $1 \mathrm{mM}$ IPTG. Cells were harvested after $4 \mathrm{~h}$ by centrifugation. The pellet was resuspended and lysed by sonication. Inclusion bodies were purified using a differential centrifugation-detergent wash procedure, ${ }^{36,37}$ with repeated washing steps (resuspension of the pellet by sonication and centrifugation) in a buffer containing $50 \mathrm{mM}$ Tris- $\mathrm{HCl} \mathrm{pH} \mathrm{7.5,}$ $100 \mathrm{mM} \mathrm{NaCl}, 1 \mathrm{mM}$ EDTA, $0.1 \% \mathrm{NaN}_{3}$, and $0.5 \%$ triton $\mathrm{X}-100$. In order to obtain a monomeric peptide solution, we employed the protocols developed by Teplow ${ }^{38}$ and Hou et al., ${ }^{39}$ with minor modifications. In brief, the peptide was dissolved in $20 \mathrm{mM} \mathrm{NaOH}$, sonicated and passed through a filter $(0.22 \mu \mathrm{m}$ pore size). The peptide solution was diluted in Tris-buffer $\left(\mathrm{pH}\right.$ 7.2) (final concentration of $\mathrm{A} \beta^{1-40}: 150 \mu \mathrm{M}$ ), seeded with preformed sonicated fibrils (12 generations of seeding), and incubated at room temperature under agitation for one week. Seeds and protocols were the same as used for the preparation of fibrils of the protonated $\mathrm{A} \beta$ peptide described previously. ${ }^{11}$ For fibril formation, the employed buffer contained $\mathrm{H}_{2} \mathrm{O}$ and $\mathrm{D}_{2} \mathrm{O}$ at mixing ratios of $\mathrm{H}_{2} \mathrm{O} / \mathrm{D}_{2} \mathrm{O}=0.5$. To exploit PRE
(Paramagnetic Relaxation Enhancement), $\mathrm{Cu}($ edta) was added to the monomeric $A \beta^{1-40}$ peptide, prior to fibrilization, at a concentration of $75 \mathrm{mM} .^{40,41}$ Growth and quality of the fibrils were monitored using EM. For each sample, typically $10 \mathrm{mg}$ of $\mathrm{A} \beta^{1-40}$ fibrils were packed into a 3.2 mm MAS solid-state NMR rotor. Proton detected ${ }^{1} \mathrm{H},{ }^{15} \mathrm{~N}$ and carbon detected ${ }^{1} \mathrm{H},{ }^{13} \mathrm{C}$ MAS solid-state NMR experiments were carried out as described previously. ${ }^{25,42}$ In the ${ }^{1} \mathrm{H},{ }^{13} \mathrm{C}$ correlation experiments, a $\mathrm{CP}$ contact time of $2.2 \mathrm{~ms}$ has been employed. Longer mixing times (up to $10.0 \mathrm{~ms}$ ) result in spectra with reduced intensities. No additional peaks were observed under these conditions. The RF field on the carbon channel was ramped and adjusted to match the $(n=-1)$ Hartmann-Hahn conditions. The rf carrier frequencies on the ${ }^{1} \mathrm{H}$ and the ${ }^{13} \mathrm{C}$ channel were set to water and to $100 \mathrm{ppm}$, respectively. ${ }^{1} \mathrm{H},{ }^{15} \mathrm{~N}$ and ${ }^{2} \mathrm{H}$ scalar decoupling during acquisition was achieved using WALTZ-16. The decoupling rf field strength on protons and nitrogen was set to $2-2.5 \mathrm{kHz}$, respectively, while an $\mathrm{rf}$ field on the order of $1.5 \mathrm{kHz}$ was employed on the deuterium channel. ${ }^{43}{ }^{13} \mathrm{C}$ detected ${ }^{1} \mathrm{H},{ }^{13} \mathrm{C}$ correlation experiments at $5{ }^{\circ} \mathrm{C}$ were performed for approximately 37 hours, while the experiment at $27^{\circ} \mathrm{C}$ was performed over 70 hours. The ${ }^{1} \mathrm{H},{ }^{15} \mathrm{~N}$ correlation experiments have been performed using a CP contact time of $1.0 \mathrm{~ms}$. The experiments were performed using a Bruker $700 \mathrm{MHz}$ quadruple resonance probe in which a deuterium coil was mounted onto the standard triple resonance setup for locking and deuterium decoupling. ${ }^{44}$ In all experiments, the MAS frequency was set to $24 \mathrm{kHz}$.

\section{Results}

In electron microscopic images, often bundles of amyloid fibrils are observed (Fig. 1A and B). So far, it has not been clear how specific these interactions are. In A $\beta$ structural models, hydrophobic interactions in the C-terminus yield an antiparallel arrangement of the protofilaments. $^{7}$ The other face of the protofilament is more hydrophilic and is not involved in tertiary contacts in all models presented so far. ${ }^{1} \mathrm{H}$ detected ${ }^{1} \mathrm{H},{ }^{15} \mathrm{~N}$ correlation spectra recorded for a perdeuterated sample of fibrils formed by $A \beta^{1-40}$ yield additional correlation peaks outside the amide backbone spectral region of 7-10 ppm and 100-130 ppm in the ${ }^{1} \mathrm{H}$ and ${ }^{15} \mathrm{~N}$ chemical shift dimension, respectively (Fig. 1C). The chemical shifts in the ${ }^{1} \mathrm{H},{ }^{15} \mathrm{~N}$ correlation suggest that these resonances are due to histidine and lysine side chain chemical groups. Amide backbone resonances have been assigned previously. ${ }^{23}$ In this manuscript, emphasis is put on the characterization of side chain exchangeable groups, in particular on the histidine resonances.

The histidine spin systems of $\mathrm{A} \beta$ can be unambiguously identified in a ${ }^{13} \mathrm{C}$ detected ${ }^{1} \mathrm{H},{ }^{13} \mathrm{C}$ correlation experiment (Fig. 1D). In this experiment, a long ${ }^{1} \mathrm{H},{ }^{13} \mathrm{C}$ cross polarization mixing step is employed which allows us to transfer magnetization from the exchangeable imidazole proton to closely spaced carbon atoms which are not directly bonded. ${ }^{25}$ The aromatic region of the spectrum is shown enlarged in Fig. 2A. Two out of the three histidines in $A \beta$ are protected from exchange. Their imidazole protons $\left(\mathrm{H} \delta_{1} / \mathrm{H} \varepsilon_{2}\right)$ have a proton chemical shift which is distinct from water. The respective ${ }^{15} \mathrm{~N}$ imidazole ring chemical shifts are on the order of 160-180 ppm which is consistent with a charged 
A)

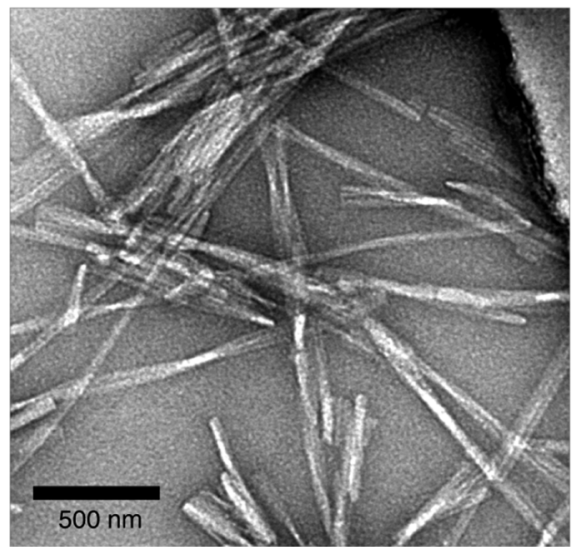

C)

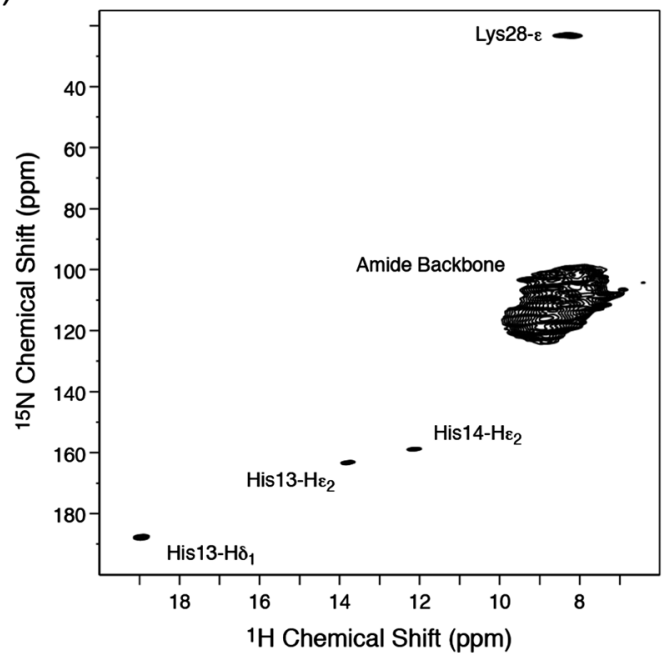

B)

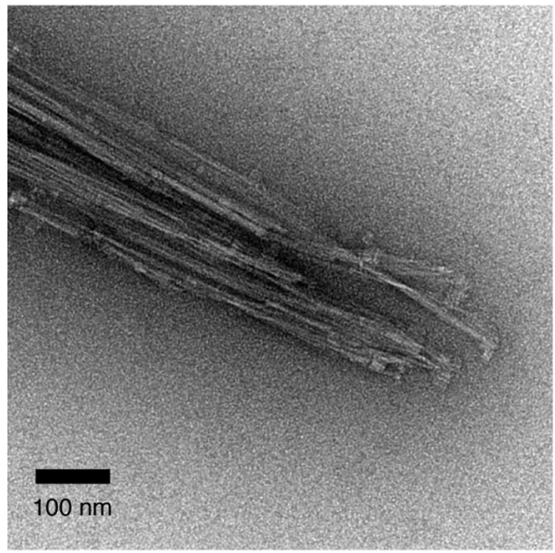

D)

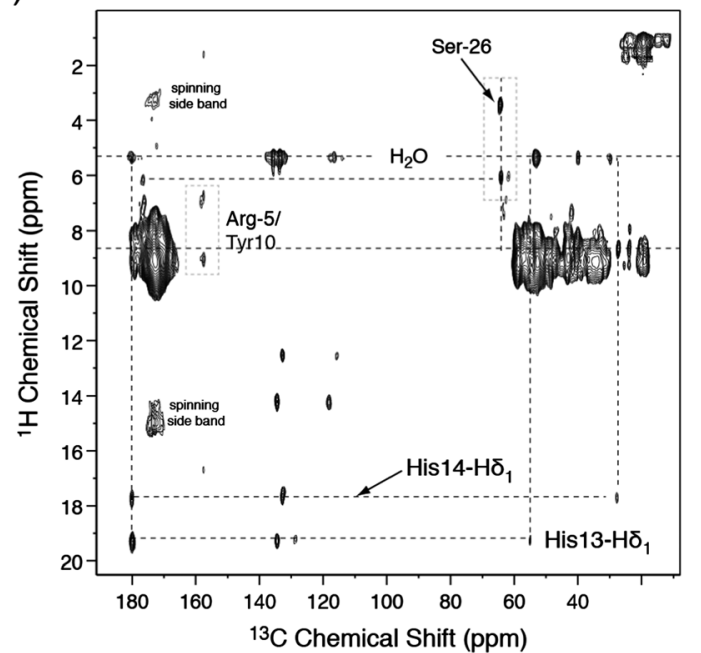

Fig. 1 (A and B) Electron microscopic images of Alzheimer's disease $A \beta^{1-40}$ amyloid fibrils employed in the MAS solid-state NMR experiments. (C) ${ }^{1} \mathrm{H}$ detected ${ }^{1} \mathrm{H}$, ${ }^{15} \mathrm{~N}$ and (D) ${ }^{13} \mathrm{C}$ detected ${ }^{1} \mathrm{H},{ }^{13} \mathrm{C}$ MAS solid-state NMR correlation spectra of peptide $A \beta^{1-40}$ fibrils using a perdeuterated peptide sample in which $50 \%$ of all exchangeable protons are deuterated. The resonance of His $14-\mathrm{H} \delta_{1}$ is not observable in the ${ }^{1} \mathrm{H},{ }^{15} \mathrm{~N}$ correlation experiment. Both experiments are recorded setting the effective sample temperature to $5{ }^{\circ} \mathrm{C}$.

imidazole ring. ${ }^{45,46}$ The histidine proton resonance which is correlated to the carbon resonance with a ${ }^{13} \mathrm{C} \varepsilon_{1}$ chemical shift of $136 \mathrm{ppm}$ is assigned to His-6, as this imidazole proton is quickly exchanged with the solvent. This interpretation is consistent with the observation that the N-terminus of the peptide in the amyloid fibril is not structured. ${ }^{11,23,47}$ Additional correlations involving the hydroxyl group of Ser-26 and arginine/tyrosine residues are observed, indicating that also these side chains are involved in tertiary contacts.

Cross peaks in the carbonyl and the aliphatic region of the ${ }^{13} \mathrm{C}$ detected ${ }^{1} \mathrm{H},{ }^{13} \mathrm{C}$ correlation spectrum (Fig. 1D) yield the assignment of the hydrogen bonding acceptor. For His13- $\mathrm{H} \delta_{1}$, correlations to a CO (180.1 ppm) and a C $\alpha$ (55.2 ppm) resonance are observed. The carboxyl correlation can be assigned to a contact between the imidazole proton and the carboxylic group at the C-terminus of the $A \beta$ peptide. This cross peak is consistent with the published $\mathrm{A} \beta(1-40)$ fibril models, ${ }^{7-10}$ in which a distance of $3-4 \AA$ between the Val-40 carboxylic group and the His-13 imidazole ring was found. The assignment of the histidine aromatic carbon chemical shifts is in agreement with a recent study in which it was found that His-13,
His-40 and the Val-40 carboxylic group are involved in binding to a $\mathrm{Cu}(\mathrm{II})$ metal ion. ${ }^{49}$ Assuming that His-13 and His-14 are located in a $\beta$-sheet secondary structure element, His-14 is facing the solvent and cannot be involved in hydrogen bonds within one protofilament. The $i, i-2$ and $i, i+2$ neighboring residues Val-12 and Lys-16 are not potential hydrogen bonding partners. A potential acceptor for the imidazole proton of His-14 is Glu-22 (Fig. 3). In the ${ }^{1} \mathrm{H},{ }^{13} \mathrm{C}$ correlation spectra (Fig. 1), His14- $\mathrm{H} \delta_{1}$ yields a contact with an aliphatic carbon with a chemical shift of $28.0 \mathrm{ppm}$. This shift is consistent with the $\mathrm{C} \gamma$ side chain chemical shift of a glutamate. The presence of this cross peak suggests that His-14 is involved in an interaction with another protofilament.

To generate the filamentous bundle model in Fig. 3, a $C_{2 \mathrm{z}}$ foldsymmetric $A \beta$ structure has been assumed. ${ }^{7}$ Formation of interfilamentous bundles, however, is not restricted to this particular fibril polymorph. $C_{2 \mathrm{x}}$ and $C_{3 \mathrm{z}}$-fold ${ }^{9}$ symmetric $\mathrm{A} \beta$ structures, as well as different quarternary arrangements which differ with respect to the side chain contacts at the internal interface (F19/M35 and F20/M35 in Petkova et al. ${ }^{7}$ ) would be compatible with the formation of 
A)
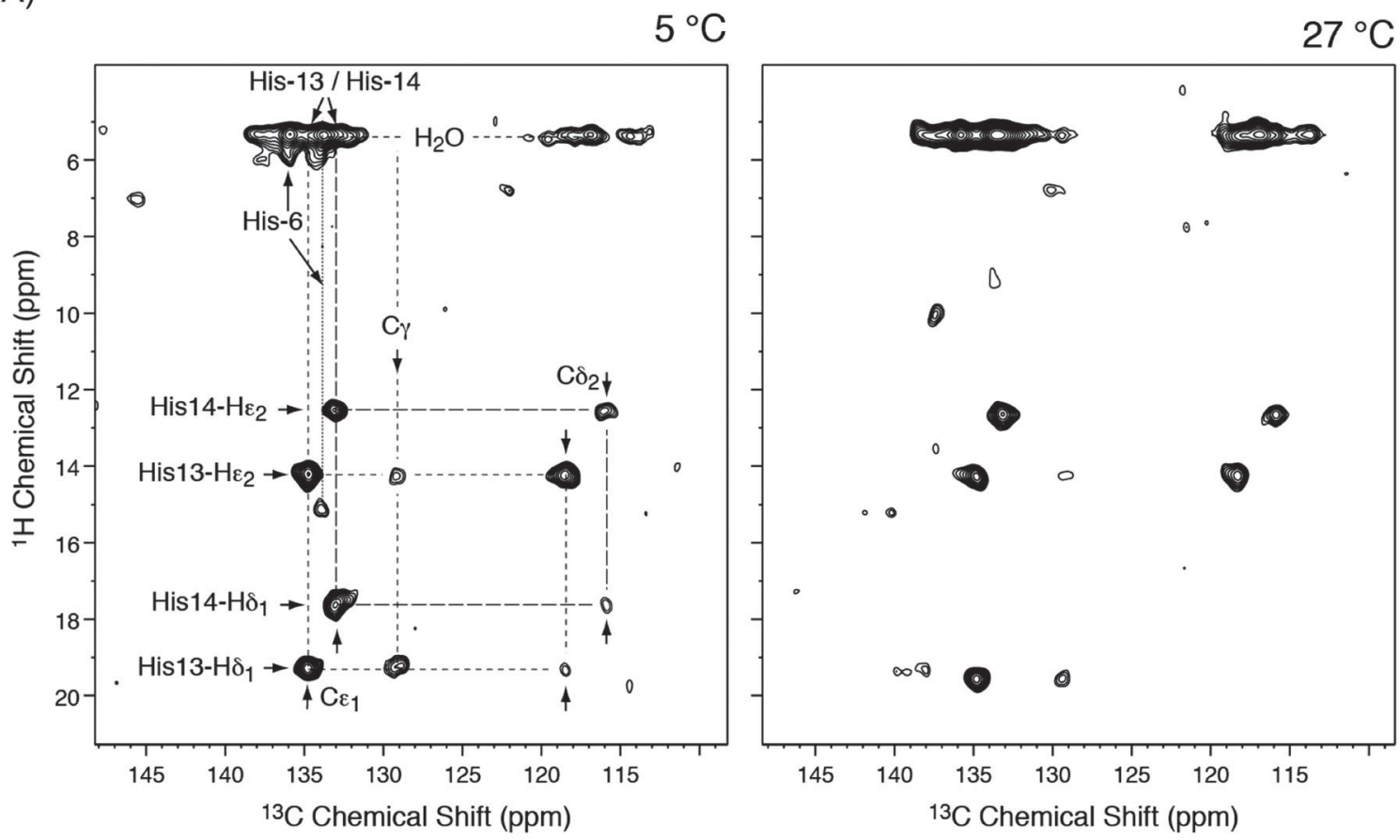

B)

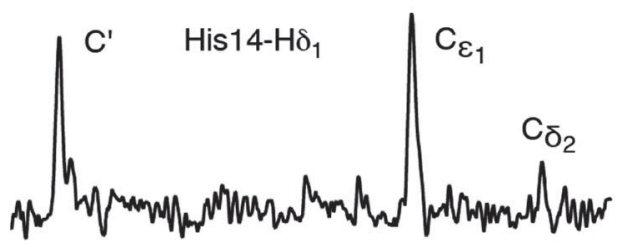

C)
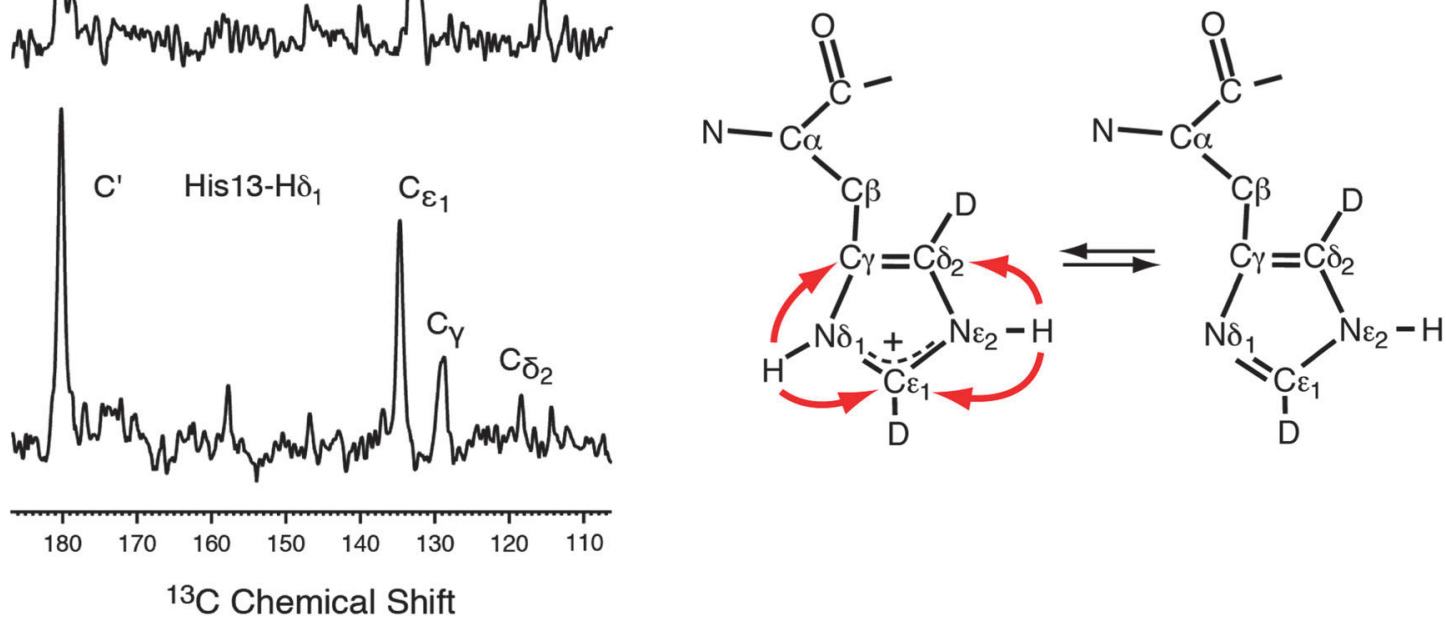

Fig. 2 (A) ${ }^{13} \mathrm{C}$ detected ${ }^{1} \mathrm{H},{ }^{13} \mathrm{C}$ correlation experiment focussing on the histidine spectral region. The experiment was recorded at an effective temperature of $5{ }^{\circ} \mathrm{C}$ (left) and $27{ }^{\circ} \mathrm{C}$ (right). At higher temperature, the His $14-\mathrm{H} \delta_{1}$ resonance is missing. (B) Rows along the ${ }^{13} \mathrm{C}$ dimension extracted from the ${ }^{1} \mathrm{H}$, ${ }^{13} \mathrm{C}$ correlation spectrum

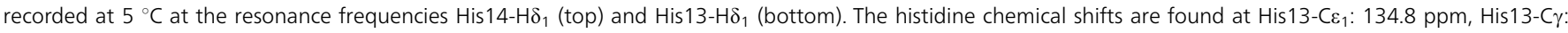

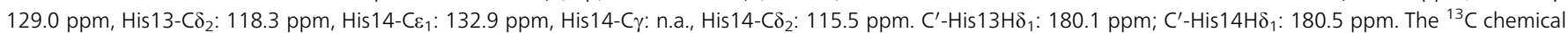
shifts are referenced using adamantane as an external standard. ${ }^{48}$ (C) Chemical structure of the protonated and the neutral histidine imidazole ring.

salt bridges between a histidine and either a glutamate or aspartic acid residue.

\section{Discussion}

We find that both His-13 and His-14 are protected from exchange and involved in tertiary interactions in the fibril preparation that we employ in our investigation. The imidazole ring of His-13 is in close proximity to the C-terminus of the $A \beta$ peptide, and seems to be another structural element to stabilize the turn. His-14, on the other hand, appears to be an important residue for inter-filament packing. We speculate that histidineglutamate side chain interactions are important features which stabilize inter-protofilament interactions. In fact, the fibrils 


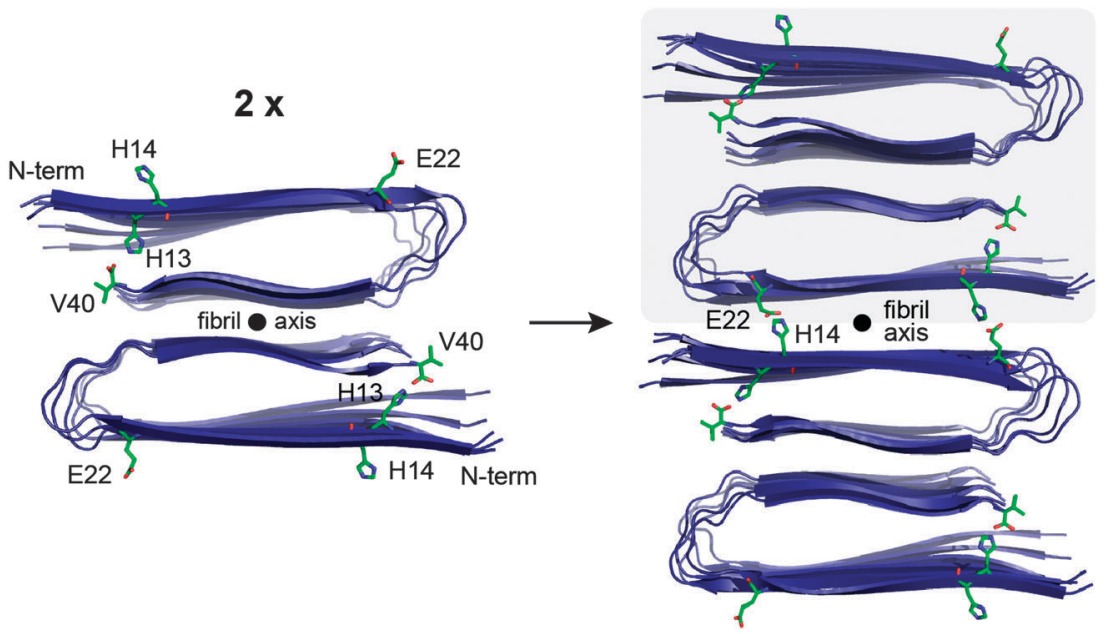

Fig. 3 Left: structural model of A 40 fibrils with $C_{2 z}$ local symmetry, according to Petkova et al. ${ }^{7}$ (PDB code: 2LMN). Right: hypothetical arrangement of a di-protofilamentous bundle stabilized by hydrogen bonding interactions between His-14 and Glu-22. Interfilamentous bundling is compatible with fibril polymorphism, as the formation of salt bridges between a histidine and either a glutamate or aspartic acid residue requires only that the sheet $\beta 1$ is located on the surface of a protofilament.

that we observe in our preparation often appear to be bundles of protofilaments.

As a consequence of conformational plasticity of $\beta 1,{ }^{13,14}$ resonances in this region can be missing due to chemical exchange broadening. Or, side chains might exist in different rotameric states. Under these pre-conditions, His-13 might be hydrogen bonded to Val-40 in one rotameric state. In another conformer, His-13 might be interacting with Glu-22. (In this scenario, His-14 would be exchange broadened.) Different rotamers could either be populated in different fibril polymorphous forms. This explanation, however, seems unlikely as the intensities of both correlations are rather similar, and the seeding protocol should result in the enrichment of a single fibril polymorph. Alternatively, different rotamers might be populated within the same polymorph. Our assignments for His-13C $\varepsilon_{1}$ and $\mathrm{His}-14 \mathrm{C} \varepsilon_{1}$ are consistent with the assignment reported by Parthasarathy et al.,${ }^{49}$ excluding this interpretation. The carboxyl carbons for which we observe correlations involving histidines in the ${ }^{13} \mathrm{C}$ detected ${ }^{1} \mathrm{H},{ }^{13} \mathrm{C}$ correlation experiment have rather similar chemical shifts. Previously, a 2 ppm chemical shift difference for Glu-22 $\mathrm{CO}^{2-}$ and Val-40 $\mathrm{CO}_{2}^{-}$was observed. ${ }^{11,49}$ The observed carboxylic carbon chemical shifts (180.1 ppm/180.5 ppm) correspond rather to Glu-22 $\mathrm{CO}^{2-}$ than to Val-40 $\mathrm{CO}_{2}{ }^{-}$. An alternative interpretation thus might imply that both His-13 and His-14 are both hydrogen bonded to Glu-22, potentially in different fibril polymorphs. The correlation between His- $13 \mathrm{H} \delta_{1}$ and a $\mathrm{C} \alpha$ resonance, and the missing correlations to side chain $\mathrm{C} \beta / \mathrm{C} \gamma$ carbons do not fit into this picture. However, due to the low signal-to-noise ratio for the aliphatic correlation peaks $(\mathrm{S} / \mathrm{N} \simeq 3: 1)$, this interpretation cannot be totally ruled out. Higherdimensional experiments including an additional chemical shift dimension need to be carried out in order to unambiguously resolve this question.

Recently, it was shown that His-13, His-14, Val-40 carboxyl and Glu side chains are involved in $\mathrm{Cu}(\mathrm{II})$ binding. ${ }^{49}$ We suggest that $\mathrm{Cu}(\mathrm{II})$ might compete for the hydrogen bonding interactions, resulting in a destabilization of the fibril structure. This might explain why addition of $\mathrm{Cu}(\mathrm{II})$ to monomeric $\mathrm{A} \beta$ results in the formation of amorphous amyloid aggregates, and adds to the conformational variability observed for the $\mathrm{N}$-terminus as described above.

The hydrogen bond involving His-14 seems to be less stable, as the correlation peak in the ${ }^{1} \mathrm{H},{ }^{13} \mathrm{C}$ correlation disappears at higher temperature. Also, the correlation peak involving $\mathrm{C} \gamma$ is missing for His-14 in all spectra. Similarly, the cross peak involving His14- $\mathrm{H} \delta_{1}$ is typically very weak in the ${ }^{1} \mathrm{H},{ }^{15} \mathrm{~N}$ correlation experiments. This in agreement with the assumption that His-14 is more dynamic as it is involved in interfilament interactions. Cross polarization (CP) is employed for magnetization transfer. Therefore, the intensities in the carbon detected ${ }^{1} \mathrm{H},{ }^{13} \mathrm{C}$ MAS solid-state NMR experiments (Fig. 2B) can be quantitatively related to the distances between the proton in the hydrogen bonding donor and the hydrogen bonding acceptor, after taking into account a potential scaling of the dipolar interaction which can be affected due to dynamic processes. The His-13 imidazole-carboxyl cross peak intensities are stronger in comparison to the cross peaks observed within the imidazole ring. This is different to what we have observed previously for a hydrogen bond involving a tyrosine hydroxyl and a carboxylic group. ${ }^{25}$ In that case, the cross peak intensities of the donor carbons were approximately two-fold stronger in comparison to the intensities of the acceptor carbon. The downfield shifted ${ }^{1} \mathrm{H}$ imidazole resonance indicates that the proton is delocalized between the donor and the acceptor group, which is consistent with what has been found for model compounds by Limbach and co-worker. ${ }^{50}$

The $\mathrm{pH}$ of the fibril sample is strictly controlled at $\mathrm{pH}$ 7.0. It is therefore surprising to see that both imidazole protons of the two histidines are observable. $\mathrm{H} \varepsilon_{2}$ can potentially be stabilized by a serine or tyrosine hydroxyl group. However, there are no 
long range correlations detectable for either His-13 $\mathrm{H}_{2}$ or His-14 $\mathrm{H} \varepsilon_{2}$, indicating that the imidazole ring might be stabilized by a water molecule. This is confirmed by correlations between water and $\mathrm{C} \varepsilon_{1}$ and $\mathrm{C} \delta_{2}$ in the ${ }^{13} \mathrm{C}$ detected ${ }^{1} \mathrm{H},{ }^{13} \mathrm{C}$ correlation experiments. At this end, it is not possible to differentiate if these peaks are due to direct correlations between water and the protein, or whether the cross peaks are exchange mediated. The positive charge of the imidazole ring is largely compensated by the negatively charged glutamic acid carboxylic group. Additionally, the imidazole ring might experience charge compensation by buffer anions, ${ }^{51}$ which seems plausible given the above discussed water accessibility.

We use here exactly the same fibril preparation protocol as in Lopez del Amo et al. ${ }^{11}$ The fibrils show a very similar morphology using electron microscopy. However, spectra are not easily superimposable even taking the deuterium isotope induced chemical shift changes into account. As in the case for assignment of the backbone amide resonances in perdeuterated $A \beta$ fibrils, ${ }^{23}$ only one set of resonances is observed. We attribute this observation to a differential thermodynamic stability of protonated and deuterated amyloid fibrils. In fact, substitution of protons with deuterium at exchangeable sites induces formation of slightly stronger hydrogen bonds. ${ }^{52}$ As amyloid aggregates are stabilized by hydrogen bonds, $\mathrm{D}_{2} \mathrm{O}$ should shift the equilibrium towards the aggregated form of the protein. ${ }^{53}$ At the same time, C-D bonds are approximately $10 \times$ stronger in comparison to $\mathrm{C}-\mathrm{H}$ bonds, resulting in a slightly shorter bond length in the case of $\mathrm{C}-\mathrm{D}$. Introduction of deuterium at nonexchangeable hydrogen positions appears to decrease non-polar interactions. ${ }^{54}$ This is in agreement with the observation that the perdeuterated $A \beta$ peptide elutes slightly earlier on a reverse phase column in comparison to the protonated peptide (data not shown). The same seeds and seeding protocols have been employed to generate the protonated and the deuterated amyloid fibril sample. All other experimental parameters are tightly controlled and kept the same in both preparations. Deuteration of exchangeable sites thus yields an increase in stability, whereas deuteration of non-exchangeable aliphatic side chains results in a destabilization of the aggregate. The relative contribution of both effects is difficult to estimate quantitatively. It seems likely, however, that even small differences in the folding energy landscape can result in a change in the amyloid fibril morphology.

Taken together, we have shown that histidine-glutamate hydrogen bonding interactions can be an important driving force for $A \beta$ fibril inter-filament packing. More experiments are needed to define the exact geometry around the histidines involved in quarternary contacts. In the future, it will be of particular interest to see how the hydrogen bonding pattern is changed if $A \beta$ oligomeric assemblies are investigated. ${ }^{55-57}$ These experiments are currently in progress in our laboratory.

\section{Acknowledgements}

We are grateful to Robert Tycko for providing us with the pdb coordinate file of the $A \beta(1-40)$ fibril structure prior to publication in the PDB. This work was performed in the framework of SFB 1035 (German Research Foundation DFG), Sonderforschungsbereich
1035, Projekt B07. R. L. was a Kekulé scholar and acknowledges financial support by the Verband der Chemischen Industrie (VCI).

\section{References}

1 D. J. Selkoe, Nature, 1999, 399, A23-A31.

2 Y. Qi-Takahara, M. Morishima-Kawashima, Y. Tanimura, G. Dolios, N. Hirotani, Y. Horikoshi, F. Kametani, M. Maeda, T. C. Saido, R. Wang and Y. Ihara, J. Neurosci., 2005, 25, 436-445.

3 G. Zhao, M. Z. Cui, G. Mao, Y. Dong, J. Tan, L. Sun and X. Xu, J. Biol. Chem., 2005, 280, 37689-37697.

4 C. S. Goldsbury, S. Wirtz, S. A. Müller, S. Sunderji, P. Wicki, U. Aebi and P. Frey, J. Struct. Biol., 2000, 130, 217-231.

5 P. T. Lansbury Jr., P. R. Costa, J. M. Griffiths, E. J. Simon, M. Auger, K. Halverson, D. A. Kocisko, A. S. Hendsch, T. T. Ashburn, R. G. S. Spenser, B. Tidor and R. G. Griffin, Nat. Struct. Biol., 1995, 2, 990-998.

6 T. S. Burkoth, T. L. S. Benzinger, V. Urban, D. M. Morgan, D. M. Gregory, P. Thiyagarajan, R. E. Botto, S. C. Meredith and D. G. Lynn, J. Am. Chem. Soc., 2000, 122, 7883-7889.

7 A. T. Petkova, W.-M. Yau and R. Tycko, Biochemistry, 2006, 45, 498-512.

8 R. Tycko, Q. Rev. Biophys., 2006, 39, 1-55.

9 A. K. Paravastu, R. D. Leapman, W.-M. Yau and R. Tycko, Proc. Natl. Acad. Sci. U. S. A., 2008, 105, 18349-18354.

10 I. Bertini, L. Gonnelli, C. Luchinat, J. Mao and A. Nesi, J. Am. Chem. Soc., 2011, 133, 16013-16022.

11 J. M. Lopez del Amo, M. Schmidt, U. Fink, M. Dasari, M. Fändrich and B. Reif, Angew. Chem., Int. Ed., 2012, 51, 6136-6139.

12 M. Schmidt, C. Sachse, W. Richter, C. Xu, M. Fandrich and N. Grigorieff, Proc. Natl. Acad. Sci. U. S. A., 2009, 106, 19813-19818.

13 R. B. Kodali, A. D. Williams, S. Chemuru and R. Wetzel, J. Mol. Biol., 2010, 401, 503-517.

14 C. Sachse, M. Fandrich and N. Grigorieff, Proc. Natl. Acad. Sci. U. S. A., 2008, 105, 7462-7466.

15 W. Qiang, W.-M. Yau, Y. Luo, M. P. Mattson and R. Tycko, Proc. Natl. Acad. Sci. U. S. A., 2012, 109, 4443-4448.

16 A. T. Petkova, G. Buntkowsky, F. Dyda, R. D. Leapman, W. M. Yau and R. Tycko, J. Mol. Biol., 2004, 335, 247-260.

17 V. Chevelkov, K. Rehbein, A. Diehl and B. Reif, Angew. Chem., Int. Ed., 2006, 45, 3878-3881.

18 V. Agarwal and B. Reif, J. Magn. Reson., 2008, 194, 16-24.

19 Ü. Akbey, S. Lange, T. W. Franks, R. Linser, A. Diehl, B. J. van Rossum, B. Reif and H. Oschkinat, J. Biomol. NMR, 2010, 46, 67-73.

20 S. Asami, P. Schmieder and B. Reif, J. Am. Chem. Soc., 2010, 132, 15133-15135.

21 P. Schanda, B. H. Meier and M. Ernst, J. Am. Chem. Soc., 2010, 132, 15957-15967.

22 J. R. Lewandowski, J. N. Dumez, U. Akbey, S. Lange, L. Emsley and H. Oschkinat, J. Phys. Chem. Lett., 2011, 2, 2205-2211.

23 R. Linser, M. Dasari, M. Hiller, V. Higman, U. Fink, J.-M. Lopez del Amo, L. Handel, B. Kessler, P. Schmieder, 
D. Oesterhelt, H. Oschkinat and B. Reif, Angew. Chem., Int. Ed., 2011, 50, 4508-4512.

24 D. H. Zhou, A. J. Nieuwkoop, D. A. Berthold, G. Comellas, L. J. Sperling, M. Tang, G. J. Shah, E. J. Brea, L. R. Lemkau and C. M. Rienstra, J. Biomol. NMR, 2012, 54, 291-305.

25 V. Agarwal, R. Linser, U. Fink, K. Faelber and B. Reif, J. Am. Chem. Soc., 2010, 132, 3187-3195.

26 L. Chen, J. M. Kaiser, T. Polenova, J. Yang, C. M. Rienstra and L. J. Mueller, J. Am. Chem. Soc., 2007, 129, 10650-10651.

27 R. Linser, U. Fink and B. Reif, J. Magn. Reson., 2008, 193, 89-93.

28 Y. Tian, L. Chen, D. Niks, J. M. Kaiser, J. Lai, C. M. Rienstra, M. F. Dunn and L. J. Mueller, Phys. Chem. Chem. Phys., 2009, 11, 7078-7086.

29 R. Linser, U. Fink and B. Reif, J. Biomol. NMR, 2010, 47, 1-6.

30 R. Linser, B. Bardiaux, V. Higman, U. Fink and B. Reif, J. Am. Chem. Soc., 2011, 133, 5905-5912.

31 M. Huber, S. Hiller, P. Schanda, M. Ernst, A. Bockmann, R. Verel and B. H. Meier, ChemPhysChem, 2011, 12, 915-918.

32 V. Chevelkov, U. Fink and B. Reif, J. Biomol. NMR, 2009, 45, 197-206.

33 A. Lange, S. Luca and M. Baldus, J. Am. Chem. Soc., 2002, 124, 9704-9705.

34 B. Reif, B. J. van Rossum, F. Castellani, K. Rehbein, A. Diehl and H. Oschkinat, J. Am. Chem. Soc., 2003, 125, 1488-1489.

35 M. J. Bayro, G. T. Debelouchina, M. T. Eddy, N. R. Birkett, C. E. MacPhee, M. Rosay, W. E. Maas, C. M. Dobson and R. G. Griffin, J. Am. Chem. Soc., 2011, 133, 13967-13974.

36 M. Carrio, N. Gonzalez-Montalban, A. Vera, A. Villaverde and S. Ventura, J. Mol. Biol., 2005, 347, 1025-1037.

37 L. Wang, S. K. Maji, M. R. Sawaya, D. Eisenberg and R. Riek, PLoS Biol., 2008, 6, e195.

38 D. B. Teplow, Methods Enzymol., 2006, 413, 20-33.

39 L. Hou, I. Kang, R. E. Marchant and M. G. Zagorski, J. Biol. Chem., 2002, 277, 40173-40176.

40 R. Linser, V. Chevelkov, A. Diehl and B. Reif, J. Magn. Reson., 2007, 189, 209-216.

41 N. P. Wickramasinghe, S. Parthasarathy, C. R. Jones, C. Bhardwaj, F. Long, M. Kotecha, S. Mehboob,
L. W. Fung, J. Past, A. Samoson and Y. Ishii, Nat. Methods, 2009, 6, 215-218.

42 R. Linser, U. Fink and B. Reif, J. Am. Chem. Soc., 2010, 132, 8891-8893.

43 V. Agarwal, A. Diehl, N. Skrynnikov and B. Reif, J. Am. Chem. Soc., 2006, 128, 12620-12621.

44 M. Huber, O. With, P. Schanda, R. Verel, M. Ernst and B. H. Meier, J. Magn. Reson., 2012, 214, 76-80.

45 W. W. Bachovchin, Biochemistry, 1986, 25, 7751-7759.

46 E. L. Ash, J. L. Sudmeier, E. C. D. Fabo and W. W. Bachovchin, Science, 1997, 278, 1128-1132.

47 A. T. Petkova, Y. Ishii, J. J. Balbach, O. N. Antzutkin, R. D. Leapman, F. Delaglio and R. Tycko, Proc. Natl. Acad. Sci. U. S. A., 2002, 99, 16742-16747.

48 C. R. Morcombe and K. W. Zilm, J. Magn. Reson., 2003, 162, 479-486.

49 S. Parthasarathy, F. Long, Y. Miller, Y. L. Xiao, D. McElheny, K. Thurber, B. Y. Ma, R. Nussinov and Y. Ishii, J. Am. Chem. Soc., 2011, 133, 3390-3400.

50 P. M. Tolstoy, J. Guo, B. Koeppe, N. S. Golubev, G. S. Denisov, S. N. Smirnov and H.-H. Limbach, J. Phys. Chem. A, 2010, 114, 10775-10782.

51 S. Narayanan and B. Reif, Biochemistry, 2005, 44, 1444-1452. 52 A. Hattori, H. L. Crespi and J. J. Katz, Biochemistry, 1965, 4, 1213-1225.

53 P. A. Baghurst, L. W. Nichol and W. H. Sawyer, J. Biol. Chem., 1972, 247, 3199-3204.

54 M. Turowski, N. Yamakawa, J. Meller, K. Kimata, T. Ikegami, K. Hosoya, N. Tanaka and E. R. Thornton, J. Am. Chem. Soc., 2003, 125, 13836-13849.

55 S. Chimon, M. A. Shaibat, C. R. Jones, D. C. Calero, B. Aizezi and Y. Ishii, Nat. Struct. Mol. Biol., 2007, 14, 1157-1164.

56 M. Ahmed, J. Davis, D. Aucoin, T. Sato, S. Ahuja, S. Aimoto, J. I. Elliott, W. E. Van Nostrand and S. O. Smith, Nat. Struct. Mol. Biol., 2010, 17, 561-568.

57 J.-M. Lopez del Amo, M. Dasari, U. Fink, G. Grelle, E. E. Wanker, J. Bieschke and B. Reif, J. Mol. Biol., 2012, 421, 517-524. 